\title{
Phase Transformation Induced by High Nitrogen Content Solid Solution in the Martensitic Stainless Steels
}

\author{
Abdelrahman Farghali ${ }^{1}$ and Tatsuhiko Aizawa ${ }^{2, *}$ \\ ${ }^{1}$ Graduate School of Engineering and Science, Shibaura Institute of Technology, Tokyo 108-8548, Japan \\ ${ }^{2}$ Department of Engineering and Design, Shibaura Institute of Technology, Tokyo 108-8548, Japan
}

A high density plasma nitriding experiment was performed on a circular disk specimen of martensitic stainless steel at the temperature of $673 \mathrm{~K}$ for $14.4 \mathrm{ks}$. The nitrided thickness was $80 \mu \mathrm{m}$ in depth from the surface with a high surface nitrogen concentration of 31 at $\%$. Scanning electron microscope (SEM), energy dispersive spectroscopy (EDX) and, electron backscattering diffraction (EBSD) were used to analyze the microstructure, the nitrogen content distribution, the phase formation, the grain size, and the straining in the specimen. Phase transformation from martensitic to austenitic phases took place together with high straining as well as grain size refinement. [doi:10.2320/matertrans.M2016418]

(Received December 8, 2016; Accepted January 13, 2017; Published February 17, 2017)

Keywords: martensitic stainless steel, low-temperature plasma nitriding, phase transformation

\section{Introduction}

Martensitic stainless steels have been used in many industrial and medical applications; they have been also modified to improve the low hardness and poor wear resistance by several diffusion treatment processes with use of the interstitial elements such as nitrogen, carbon, and boron ${ }^{1)}$. Liquid and gas nitriding were traditional methods to diffuse nitrogen into the surface of stainless steel alloys together with precipitation of nitrides ${ }^{2}$. These two methods have many drawbacks; e.g. the energy consumption by high-temperature processing, the formation of brittle white layers, and the risk of environmental pollution. Instead of them, the plasma-based nitriding processes have been highlighted; e.g. the plasma nitriding, the ion implantation, and the plasma immersion ion implantation $^{3,4)}$. These new methods have advantages in terms of quality, repeatability, and environmental friendliness by controlling the pressure, the temperature and the nitrogen gas flow $^{5)}$.

The plasma nitriding significantly improves the hardness and wear resistance of stainless steels. The corrosion resistance was highly affected by the holding temperature in this nitriding. In the case of high-temperature plasma nitriding (HT-PN), above $723 \mathrm{~K}$, the chromium nitrides $(\mathrm{CrN})$ precipitate in the nitrided layer; reduction of the chromium content results in deterioration of corrosion resistance. On the other hand, no nitrides precipitate in the low-temperature plasma nitriding (LT-PN), below $723 \mathrm{~K}^{6-8)}$.

In this LT-PN, the nitrogen diffusion process without precipitation of nitrides takes place to form the expanded phases; e.g. the formation of expanded austenitic phases ${ }^{9-11)}$, and, the formation of expanded martensitic phases ${ }^{12-14)}$. In particular, this expansion in the martensitic stainless steels has a possibility to accompany with the phase transformation from martensite $\left(\alpha^{\prime}\right)$ to austenite $(\gamma)$ by high nitrogen concentration of 20 at $\%$. Furthermore, this high nitrogen concentration over 20 at $\%$ is expected to induce high straining into the original crystalline structure. Hence, the martensitic lattice expansion

*Corresponding author, E-mail: taizawa@sic.shibaura-it.ac.jp by high nitrogen concentration drives the high straining, the grain size refinement, and the phase transformation through LT-PN.

In the present study, the RF/DC plasma nitriding process with use of the hollow cathode device is employed to make low-temperature plasma nitriding of AISI420 substrates under the high nitrogen ion density. SEM-EDS, XRD, and EBSD are utilized to make a precise analysis of the nitrided specimen and to describe the relations among the high nitrogen solid solution, the high straining, the refinement in microstructure, and the phase transformation.

\section{Experimental Procedure}

A high-density plasma nitriding system was used in the following experiments. The system consisted of the vacuum chamber, the evacuation system, the DC-RF generator working in the frequency of $2 \mathrm{MHz}$, the gas supply of $\mathrm{N}_{2}$ and $\mathrm{H}_{2}$, and, the heating unit located under the cathode plate as illustrated in Fig. 1. In the vacuum chamber, the specimen was placed inside a hollow cathode setup on the cathode plate, which was electrically connected with DC generator. Both nitrogen and hydrogen ions were confined inside the setup to attain the nitrogen ion density of $3 \times 10^{17}$ ions $/ \mathrm{m}^{315}$ )

After placing the sample into the hollow cathode setup, the chamber was evacuated down to $0.5 \mathrm{~Pa}$ in pressure, and, then filled with the nitrogen gas with the flow rate of $160 \mathrm{ml} / \mathrm{min}$ until the pressure was constant by $60 \mathrm{~Pa}$. Next, the sample was pre-sputtered for $1.8 \mathrm{ks}$ to remove any oxide passive layer from its surfaces. This pre-sputtering process operated at $673 \mathrm{~K}$ using the DC discharge of $350 \mathrm{~V}$ in pure nitrogen gas by $300 \mathrm{~Pa}$. After pre-sputtering, it was plasma nitrided for $14.4 \mathrm{ks}$ or four hours at the holding temperature of $673 \mathrm{~K}$ or $400^{\circ} \mathrm{C}$ by $60 \mathrm{~Pa}$ in pressure. The mixture of nitrogen and hydrogen gasses was provided to have the ratio of $160 \mathrm{ml} / \mathrm{min}$ for nitrogen to $30 \mathrm{ml} / \mathrm{min}$ for hydrogen. Detailed parameters are summarized in Table 1. After the nitriding process, the sample was cooled in the vacuum chamber to minimize the possibility of surface contamination.

The material used in this study was martensitic stainless 


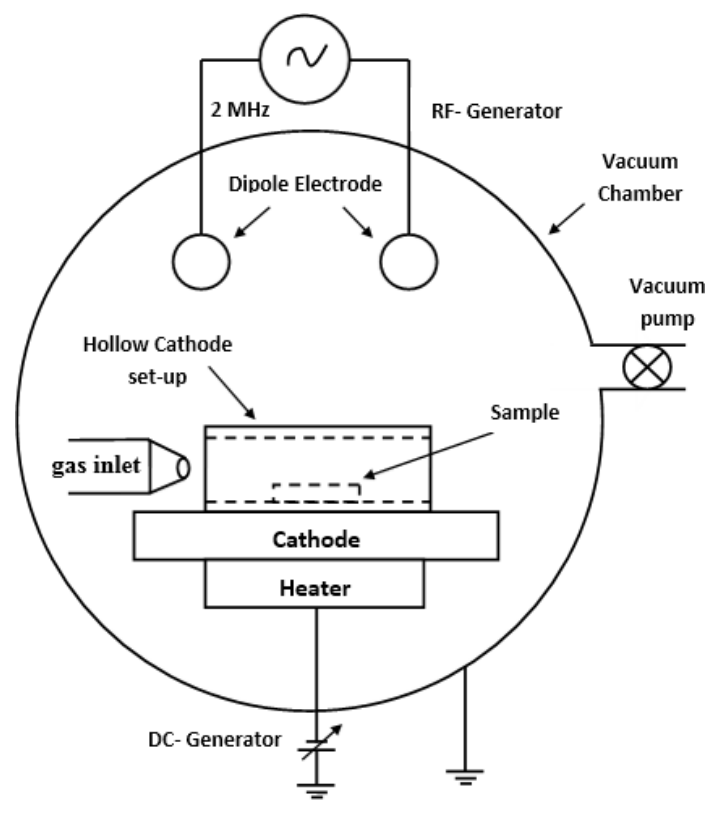

Fig. 1 Illustration of the present high-density plasma nitriding system including the hollow cathode set-up.

Table 1 Standard processing parameters for the present plasma nitriding.

\begin{tabular}{lll}
\hline Parameter & Pre-Sputtering & Plasma nitriding \\
\hline Temperature (K) & 673 & 673 \\
Pressure (Pa) & 300 & 60 \\
RF-Voltage (V) & 250 & 250 \\
DC-Voltage (V) & 350 & 500 \\
Gas Flow (ml/min) & $160 \mathrm{~N}_{2}$ & $160 \mathrm{~N}_{2}, 30 \mathrm{H}_{2}$ \\
Gas ratio (\%) & $100 \% \mathrm{~N}_{2}$ & $84 \% \mathrm{~N}_{2}+16 \% \mathrm{H}_{2}$ \\
Duration (s) & 1800 & 14400 \\
\hline
\end{tabular}

steel AISI-SUS 420-J2 with a chemical composition of $\mathrm{C}<$ $0.15 \%, \mathrm{Mn}<1 \%, \mathrm{P}<0.04 \%, \mathrm{~S}<0.03 \%, \mathrm{Si}<1 \%, \mathrm{Cr}<$ $12 \sim 14 \%$, and $\mathrm{Fe}$ in balance. A circular disk sample with a diameter of $25 \mathrm{~mm}$ and thickness of $5 \mathrm{~mm}$ was prepared. Before nitriding, this sample was degreased by an ultrasonic cleaner system (Sono Cleaner 200DL) with an alkaline solution to remove any surface contaminant layer.

After the plasma nitriding process, the sample was analyzed by the X-ray diffractometer (XRD). XRD (Rigaku, SmartLab) was operated with the monochromatic CuKa radiation $(\lambda=0.1542 \mathrm{~nm})$ and the Bragg-Brentano geometry $\left(40 \mathrm{kV}, 30 \mathrm{~mA}\right.$,). In measurement, $2 \theta$ ranged from $30^{\circ}$ to $90^{\circ}$ with the scanning speed of $5 \mathrm{~mm} / \mathrm{min}$ and the step angle of $0.02^{\circ}$. The sample was cut in half and mechanically polished using SiC sand papers with roughness grades from \#150 to \#4000 and the alumina powder solution with the $\mathrm{Al}_{2} \mathrm{O}_{3}$-particle size of $1,0.3$, and, $0.05 \mu \mathrm{m}$. In finishing, an ion milling system (HITACHI- IM400) with argon (Ar) gas was used to achieve mirror-like surface for the following analyses. The surface was degreased and cleaned ultrasonically. The microstructure of the nitrided layer was analyzed by scanning electron microscope (SEM). Energy dispersive spectroscopy (EDS) and electron backscattering diffraction (EBSD; HITACHI SU-70) were employed to make a precise analysis.

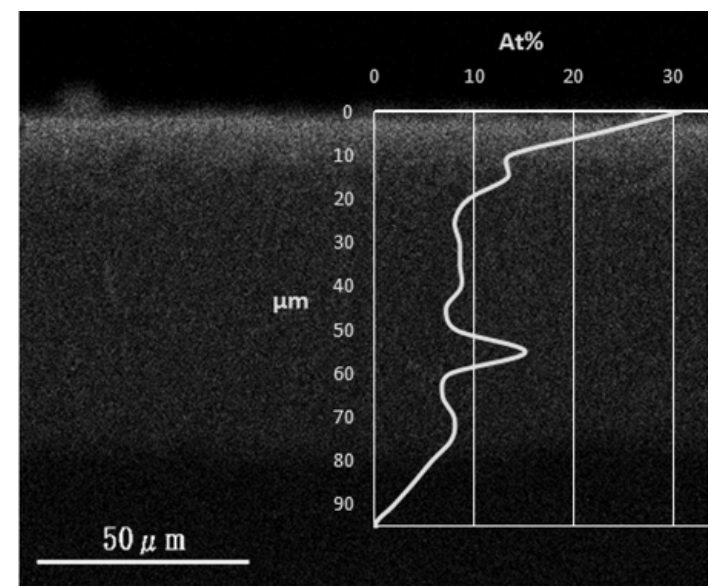

Fig. 2 EDS nitrogen mapping on the cross-section of the plasma nitride AISI420-J2 specimen at $693 \mathrm{~K}$ for $14.4 \mathrm{ks}$ with nitrogen concentration in the depth profile.

\section{Results and Discussions}

Figure 2 shows the EDS nitrogen mapping together with the nitrogen content depth profile. Highly concentrated nitrogen atoms are present from 31 at $\%$ to 10 at $\%$ at the vicinity of surface down to $20 \mu \mathrm{m}$ in depth. The nitrogen contents detected are much higher than the solubility limit of 0.08 at \%; no chromium nitride $(\mathrm{CrN})$ precipitates are detected. The plateau of nitrogen content is observed to have almost 9 at $\%$ from $20 \mu \mathrm{m}$ to $80 \mu \mathrm{m}$ in depth. The high nitrogen concentration at the surface is responsible for driving the nitrogen diffusion process down to the nitriding front end at $80 \mu \mathrm{m}$ in depth. This nitrogen diffusion process accompanies with occupation process of nitrogen solute atoms into octahedral vacancy sites in the $\alpha^{\prime}$-bcc martensitic lattice structure. This occupation process is detected as an $\alpha^{\prime}$-lattice expansion by XRD analysis.

High anisotropic straining is theoretically predicted in Ref. 16) for the expanded martensitic super lattice in the a-, b-, and c-axes by high nitrogen concentration; e.g., significantly large strain expansion is expected to occur by $\varepsilon_{001}$ » $\varepsilon_{100}=\varepsilon_{010}$. Imai et al. ${ }^{17)}$ reported the expansion and contraction diagram of lattice parameters in the a-, b- and c-axes with the nitrogen content. This diagram is extrapolated in the higher nitrogen contents to estimate that bcc lattice expands by $39 \%$ in c-axis and contracts by $2.3 \%$ in both a- and b-axes with the c/a ratio of 1.425 , at $[\mathrm{N}]=31$ at $\%$. In the polycrystalline structure, each grain or each sub-grain including the nitrogen solutes is forced to expand in the c-axis; the whole grains in the nitrided layer in Fig. 2 are subjected to the high distortion by this lattice expansion ${ }^{18}$.

Figure 3 (a) shows the inverse pole figure (IPF) of grain sizes and multiple lattice orientations after EBSD. Below the nitriding front end at $80 \mu \mathrm{m}$ in depth, the original grains remain as they were before nitriding. Refinement of grain size takes place only in the nitrided layer; small-sized grains and high angle grain boundaries distribute from the surface layer down to $20 \mu \mathrm{m}$ depth.

In EBSD, the kernel average misorientation (KAM) represents the strain concentration; i.e. high KAM indicates the highly strained region. As shown in Fig. 3 (b), the highly 


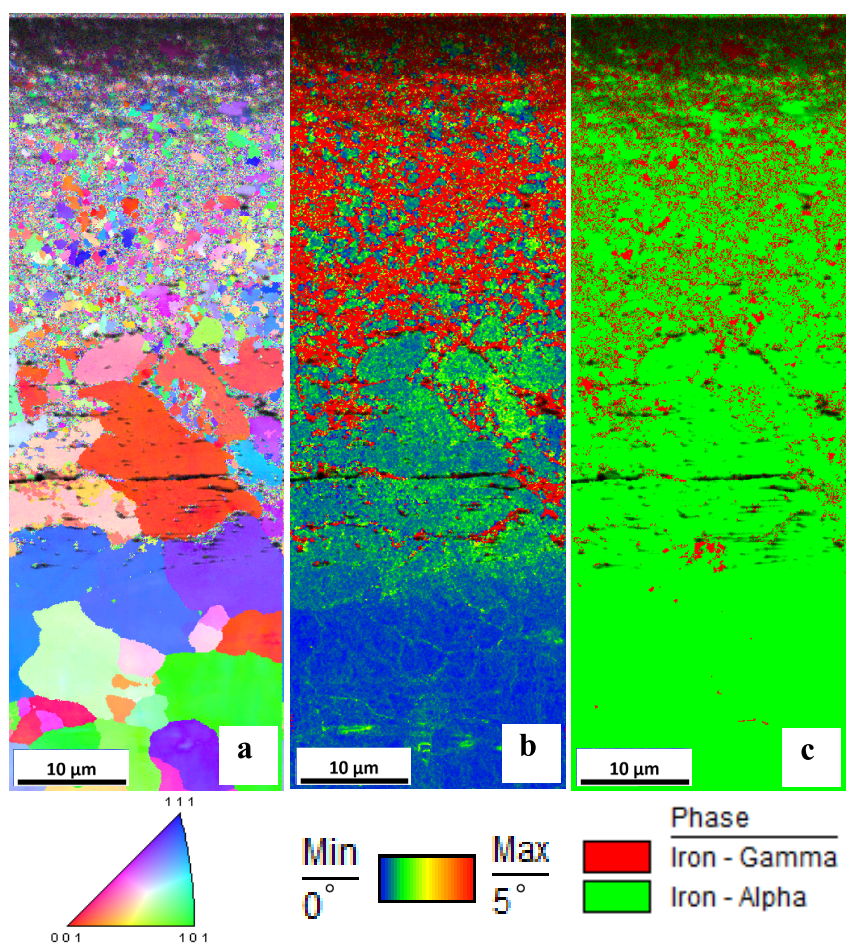

Fig. 3 Electron backscattered diffraction (EBSD) crystallographic images of martensitic stainless steel AISI-J2 specimen. (a) the IPF map of the grain size, (b) the KAM strain mapping, and, (c) the mapping of the austenitic and martensitic phases.

strained zones never distribute homogeneously in the nitrided layer; they form the network structure where low strained grains or subgrains are surrounded by the highly strained subgrains. Considering that the distortion tensor is divided into the spin rotations and the true strain tensors, the distortion by the high nitrogen concentration into the $\alpha^{\prime}$-lattice induces the grain refinement of original grains and subgrains as well as the spin-rotation of subgrains to form the highly strained network structure.

After electron diffraction by EBSD, the bcc-structured grains and subgrains are distinguished from the fcc-structured ones. Figure 3 (c) depicts the martensitic and austenitic phase distributions. The austenitic phase distributes in the similar network structure as seen in Fig. 3 (b); the transformation from the original martensitic phase to the austenitic one is driven by high straining in the nitrided layer. In accordance with the nitrogen depth profile in Fig. 2, the volume fraction of austenite phases decreases with depth. The average volume fraction reaches $19 \%$ in the nitrided layer.

With reference to the polar diagram in Fig. 3 (a) and the phase mapping in Fig. 3 (c), the sub-grains with the austenitic phase at the vicinity of the surface have the orientations of [001], [112] or [102]. The sub-grains with [101] and [111] remain to be martensitic. However, in the lower part of the nitrided layer, the austenitic transformation takes place in the sub-grains only with the orientation of [001], and, the subgrains with [112] and [102] remain its original martensitic structure. Just as seen in the volume fraction depth distribution of austenitic phases, the phase transformation process depends on the nitrogen concentration. When the nitrogen contents become higher than 8 to 10 at $\%$ in the nitrided layer,

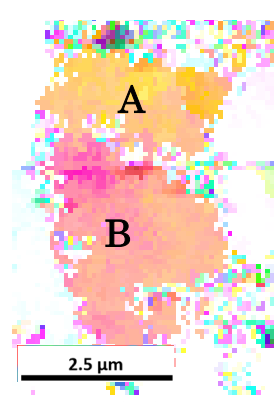

(a)

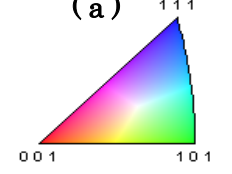

Fig. 4 EBSD analysis in local at the depth of $35 \mu \mathrm{m}$ from the surface. (a) the IPF map of the grain size (b) the KAM strain mapping (c) the austenitic and martensitic phase distribution.

the grains and sub-grains are expanded in the c-axis to strain themselves enough to make transformation to austenitic phase along [001] direction.

Two adjacent sub-grain sets A and B located at the depth of $35 \mu \mathrm{m}$ in Fig. 4 (a) are precisely analyzed by EBSD. The set-A has the major orientation of [112] with the minor orientation of [001]. The set-B has two major orientations of [112] and [001]. The region with [112] locates in its right and left lower sections while the region with [001], in its upper section. These two sets are surrounded by the highly-straining network structure where the grains are refined together with the phase transformation as shown in Figs. 4 (b) and (c). In the inside of these two sets, the sub-grains with the orientation in [001] are strictly expanded to transform themselves to be austenitic. While the sub-grains with the orientation of [112] remain to be martensitic in Figs. 4 (a) and 4 (c).

\section{Conclusion}

Transformation from martensitic to austenitic phases by high nitrogen solid solution was investigated by using the high-density plasma nitriding at $673 \mathrm{~K}$ for $14.4 \mathrm{ks}$. Main conclusions were summarized in the following.

(1) Nitrogen solute content becomes 31 at $\%$ at the surface and gradually decreases with the depth down to $80 \mu \mathrm{m}$.

(2) This high concentration induces the bcc-lattice distortion; these lattice strains in the c-axis and in the a/b-axes are estimated to be $39 \%$ in expansion and $2.3 \%$ in contraction, respectively.

(3) Highly strained grains and sub-grains form a network structure. This network becomes dense enough to make grain refinement in the whole region near the surface. The network density gradually becomes sparse; grain refinement takes place only along this network.

(4) Original martensitic phase transforms by $19 \%$ to austenite throughout the whole nitrided layer.

(5) In its lower region, the sub-grains with the orientation of [001] selectively transform to be austenitic. Other subgrains with the [112] or [102] orientations never transform and remain to be martensitic. 


\section{Acknowledgments}

The authors would like to express their gratitude to Mr. T. Shiratori, Mr. T. Yoshino and Mr. Y. Suzuki (Komatsu-Seiki Kosakusho, Co. Ltd.) and Mr. H. Morita (Nano-Coat Laboratory, LLC) for their help in measurement. This study is financially supported by the ABE-Initiative Program, Japan Government.

\section{REFERENCES}

1) X. Yun-tao, L. Dao-xin and H. Dong: Appl. Surf. Sci. 254 (2008) 5953 5958.

2) J. Flis, J. Mankowski and E. Rolinski: Surf. Eng. 5 (1989) 151-157.

3) R. Wei, J.J. Vajo, J.N. Matossian, P.J. Wilbur, J.A. Davis, D.L. Williamson and G.A. Collins: Surf. Coat. Tech. 83 (1996) 235-242.

4) O. Öztürk and D.L. Williamson: J. Appl. Phys. 77 (1995) 3839-3850.

5) T. Aizawa and H. Kuwahara: Mater. Trans. 44 (2003) 1303-1310.

6) C. Blawert, B.L. Mordike, U. Rensch, G. Schreiber and H. Oettel: Surf.
Eng. 18 (2002) 249.

7) N. Granito, H. Kuwahara and T. Aizawa: J. Mater. Sci. 37 (2002) 835844.

8) C.X. Li and T. Bell: Corros. Sci. 48 (2006) 2036-2049.

9) C. Blawert, B.L. Mordike, Y. Jiraskova and O. Schneeweiss: Surf. Coat. Tech. 116-119 (1999) 189.

10) M. Samandi, B.A. Shedden, D.I. Smith, G.A. Collins, R. Hutching and J. Tendys: Surf. Coat. Tech. 59 (1993) 261.

11) S. Mandl and B. Rauschenbach: J. Appl. Phys. 91 (2002) 9737.

12) S.K. Kim, J.S. Yoo, J.M. Priest and M.P. Fewell: Surf. Coat. Tech. 163164 (2003) 380-385.

13) I. Alphonsa, A. Chainani, P.M. Raole, B. Ganguli and P.I. John: Surf. Coat. Tech. 150 (2002) 263.

14) A. Leyland, D.B. Lewis, P.R. Stevenson and A. Matthews: Surf. Coat. Tech. 62 (1993) 608.

15) T. Aizawa and Y. Sugita: Res. Rep. SIT 57-1 (2013) 1-10.

16) C. Domain, C.S. Becquart and J. Foct: Physical Review B 69 (2004) 114112.

17) Y. Imai, M. Izumiyama and M. Tsuchiya: the res. Inst. Tohuku Univ. A17 (1965) 173.

18) A. Farghali and T. Aizawa: Proc. $10^{\text {th }}$ SEATUC, Tokyo (2016) (CDROM). 